\title{
Experiências transdisciplinares do Projeto de Extensáo Universitária Oceanos com estudantes em situaçáo de vulnerabilidade social
}

\author{
Kátia Naomi Kuroshima ${ }^{1}$ \\ https://orcid.org/0000-0002-4261-9878 \\ Ana Lucia Berno Bonassina ${ }^{2}$ \\ https://orcid.org/0000-0001-5279-0823 \\ José Matarezi ${ }^{3}$ \\ https://orcid.org/0000-0002-6890-8811 \\ Manoela Tormen Criveletto Canalli Pacheco ${ }^{4}$ \\ https://orcid.org/0000-0002-2215-1489 \\ Camila Burigo Marin 5 \\ https://orcid.org/0000-0002-3901-0033 \\ Nayara Martins Orsi ${ }^{6}$ \\ https://orcid.org/0000-0003-3374-7824
}

${ }^{1}$ Graduada em Oceanologia (FURG), Mestre em Geocências (UFF) e Doutora em Química Orgânica (UFSC). Docente, pesquisadora e extensionista na Universidade do Vale do Itajaí. E-mail: kurohima@univali.br.

${ }^{2}$ Bacharel em Informática (Unicenp); Graduada em Pedagogia (ULBRA), Mestre em Educaçâo (PUC-PR). Doutoranda em Ciência e Tecnologia Ambiental (UNIVALI) e pedagoga (IFPR). E-mail: ana.bonassina@ifpr.edu.br.

${ }^{3}$ Graduando em Oceanografia (FURG). Especialista em Análise e Educaçáo Ambiental (UFPR). Mestre e Doutorando em Patrimônio Cultural e Sociedade na UNIVILLE. E-mail: jmatarezi@univali.br.

${ }^{4}$ Graduada em Oceanografia (UNIVALI).E-mail: manoelapacheco@univali.br.

5 Graduada em Oceanografia (UNIVALI), Mestre em Oceanografia (FURG), Doutorado em Ciência e Tecnologia Ambiental (UNIVALI). E-mail: camilamarin@univali.br.

6 Graduada em Oceanografia (UNIVALI), Pós-Graduanda em Especializaçâo em Direitos Humanos, Responsabilidade Social e Cidadania Global. E-mail: E-mail: nayara orsi@hotmail.com. 


\title{
Resumo
}

Estudos têm mostrado que o distanciamento entre homem e ambiente, imposto pela sociedade urbana, tecnológica e consumista é promotor dos desastres ambientais. A educação pode reverter estes cenários, mas, ainda enfrenta um de seus maiores desafios, o pensar de uma forma íntegra, do ser humano consigo mesmo, com o próximo e com o meio ambiente. Esta pesquisa de abordagem quali-quantitativa compreendeu o relato e a análise de duas práticas teóricometodológicas transdisciplinares do Projeto de Extensão Oceanos, denominadas Árvore Semântica do Conhecimento - ASC, aplicadas em 2018 e 2019, com 200 e 60 estudantes, respectivamente, em situação de vulnerabilidade social, do município de Itajaí-SC. Dois aspectos parecem ter sido necessários e essenciais para a efetivação da ASC: a sensibilização para a contextualização aos problemas ambientais e conhecimento prévio sobre os diferentes saberes dos estudantes. A sua aplicação demonstrou ser um recorte no tempo e espaço onde razão e emoção, objetividade e subjetividade podem trabalhar juntos, mudando as percepções e modos de ver e interpretar a realidade impactando na construção coletiva do conhecimento. Desta forma, o processo de aprendizagem deverá ser participativo, autônomo e protagonista para que as relaçóes causa/efeito sejam mais profundas, complexas, abrangentes e transdisciplinares.

Palavras-chave : Extensão universitária, Transdisciplinaridade, Razão/emoção, Meio ambiente, Sustentabilidade.

\section{Transdisciplinary challenges of the Oceanos University Extension Project with students in situations of social vulnerability: mapping prior knowledge by creative methodologies}

\begin{abstract}
Studies have shown that the distance between man and the environment, imposed by an urban, technological, and consumerist society is the cause of environmental disasters. Education can reverse these scenarios, but, it still faces one of its biggest challenges, the thinking in an integral way of the human being with himself, with others, and with the environment. This qualiquantitative approach research relied on the report and analysis of two transdisciplinary theoricmethodological practices of the Oceanos Extension Project called Semantic Tree of Knowledge (ASC), applied in 2018 and 2019 with 200 and 60 young people, respectively, in the situation of social vulnerability, from the municipality of Itajaí-SC. Two aspects seem to have been necessary and essential for the implementation of the ASC: awareness of the contextualization to environmental issues and previous information about the different knowledge of the students. Its application has proven to be a cutout in time and space where reason and emotion, objectivity and subjectivity can work together, changing perceptions and ways of seeing and interpreting reality impacting the collective construction of knowledge. In this way, the learning process must be participative, autonomous, and protagonist so that the cause-effect relationships are deeper, more complex, comprehensive, and transdisciplinary.
\end{abstract}

Keywords: University extension, Transdisciplinarity, Reason/motion, Environment, Sustainability. 


\section{Introduçáo}

Desastres ambientais estão cada vez mais comuns no cotidiano. $\mathrm{O}$ exemplo mais contemporâneo deste impacto é a pandemia do novo coronavírus (COVID-19), que assola a humanidade nos últimos meses, abalando todos os aspectos de vida em sociedade, forçando a uma readequação de valores sociais, econômicos, culturais, estéticos e éticos.

Além da pandemia, outros fenômenos, como enchentes, secas e demais eventos extremos, alertam para a relação insustentável do homem com o planeta em que vive. O município de Itajaí, localizado na foz do rio Itajaí-açú, é uma das regióes mais atingidas por enchentes no estado de Santa Catarina, problema que vem se agravando devido ao crescimento urbano acelerado sem planejamento, incluindo desmatamento de matas nativas e ocupação de áreas inundáveis às margens do maior rio que percorre o estado. Município litorâneo, tem a sua economia fortemente dependente dos elementos da natureza. As atividades presentes na região são: pesqueira, portuária, turismo de veraneio, todas atuam mutuamente, concorrendo e dependendo dos mesmos recursos naturais. Apesar da forte dependência do meio ambiente, $o$ descuido para com este é um fator preocupante.

A falta de pertencimento ao local, imposto por uma sociedade urbanizada, tecnológica e consumista, mesmo que dependa diretamente dos seus recursos, pode ser um dos pilares para negligenciar o meio ambiente, refletindo nos desastres ambientais. A educação pode auxiliar na reversão destes processos, aproximando o homem do seu entorno, provocando reflexôes sobre estas problemáticas e, consequentemente, mudando os seus hábitos. No entanto, pensar de uma forma íntegra, o homem consigo mesmo, com o próximo e com o meio ambiente é um dos maiores desafios a serem enfrentados pela educação neste século.

Gadotti exalta em seu livro "Educação Integral no Brasil” a importância de se educar para e pela cidadania, de criar hábitos de estudo e pesquisa, cultivar hábitos alimentares, de higiene, ambientais e ampliar a aprendizagem dos estudantes além do tempo em sala de aula, ou seja, "oferecer mais oportunidades de aprendizagem para todos os alunos” (GADOTTI, 2009, p.38

O Projeto Oceanos, consoante às ideias de Gadotti (2009) que traz a educação integral como oportunidade a todos, e Freire (1996), que alerta para 
os diferentes saberes, experiências e conscientização socio-histórico-culturais, tem a proposta de aproximar a comunidade do seu entorno. Concebido, a princípio, como uma atividade universitária extensionista, mas indo além desta base, tem trabalhado conceitos ambientais de forma interdisciplinar e transdisciplinar com estudantes em situação de vulnerabilidade social no município de Itajaí, Santa Catarina. Desenvolve atividades fundamentadas em metodologias de trabalho que se organizam em um ciclo contínuo e sistematizado, envolvendo o "planejar/executar/ avaliar/ sistematizar/ socializar", partindo da curiosidade dos estudantes e transformando-os em experiências investigativas, tornando-os indivíduos ativos e participativos na elaboração e planejamento das atividades, promovendo o fator motivacional sempre presente em todas elas, como um facilitador do processo de aprendizagem.

As atividades do Projeto Oceanos realizaram-se no contraturno escolar, no modelo de educação não formal. Este formato permite maior liberdade nos conteúdos trabalhados, sem ter o compromisso com o cumprimento dos conteúdos obrigatórios do currículo escolar, favorecendo o trabalho interdisciplinar; respeitando as diferenças sociais, culturais e éticas, e principalmente, a necessidade de adequação das atividades às características de cada estudante, convergindo para uma formação humana, mais colaborativa, humanitária, de compreensão mútua diante do pensamento divergente, estimulando uma postura dialógica e pacífica frente aos conflitos surgidos.

Este processo de aprendizado de forma orgânica, natural e cíclica possibilita a formação de um indivíduo integral e humanizado, numa perspectiva crítica, emancipatória e transformadora, capaz de ampliar a autonomia e a "potência de agir", integrando o conhecimento sensível e inteligível, concomitante, preparando os estudantes para os desafios contemporâneos no enfrentamento das sucessivas crises socioambientais. Estas crises, em escala local e global, provocam profundas alteraçóes no planeta (ZALASIEWICZ et al., 2011), entre elas, o aquecimento global, a escassez de recursos naturais, entre outros.

\section{Fundamentaçáo metodológica}

É evidente que vive-se um período de negligência total do meio ambiente. Há a necessidade urgente de um reposicionamento da visão 
antropocêntrica para um novo modelo civilizatório onde a convivência social, ambiental e ética sejam priorizados. O ser humano precisa reconhecer a interdependência com todos os outros seres viventes (MORAES, 2019a) e, desta forma, conviver em harmonia com o meio ambiente. A educação exerce um papel fundamental nesta transformação quando prioriza a discussão, reflexão e uma abordagem crítica sobre os problemas ambientais atuais e pertinentes (FIGUEIREDO, 2006).

Os conflitos e necessidades de entender a realidade do mundo presente, sem negar nem dividir o conhecimento, precisam ser tematizados. A urgência em superar modelos que visam à reproduçáo do conhecimento, o estudo fragmentado, descontextualizado e conteudista, possibilita novos movimentos com vistas a romper velhos modelos e buscar novas formas de abordar os problemas contemporâneos. Behrens (2003, p. 25) complementa: "a fragmentaçáo do conhecimento tem sido focalizada como o maior desafio a ser transposto para acompanhar o paradigma da complexidade e os desafios impostos pela Sociedade do Conhecimento".

Em contraponto à fragmentação do conhecimento, Capra (1996), Behrens (2003) e Moraes (2019) congregam a ideia da indissociabilidade entre o indivíduo e o contexto, quando contestam o paradigma newtonianocartesiano, mecanicista e fragmentado, e passam a tratar o conhecimento como "[...] uma complexa teia de relaçóes entre as várias partes de um todo unificado [...]" (CAPRA, 1996, p.32), buscando açóes pedagógicas problematizadoras e desafiadoras, possibilitando aos estudantes o trabalho coletivo, aliado ao individual, desafiando-o a investigar, propor e contribuir com novas ideias e novas possibilidades para soluçóes de problemas ambientais que nos sáo apresentados cotidianamente.

A educação, para a reforma do pensamento, é uma solução estratégica para os problemas ambientais. Outras racionalidades, mais sensíveis e ambientais, devem ser apreendidas na prática, no cotidiano e devem colaborar para a formação de cidadãos conscientes e proativos enquanto coletividade. Os abalos sofridos pelos princípios da ordem, da separação, da redução e da validação da lógica clássica 'dedutiva-indutiva-identitária' ao longo do desenvolvimento científico do século $\mathrm{XX}$, sem que se tenha pensado na necessidade de uma profunda reforma do pensamento, se caracterizam como os maiores desafios da complexidade (MORIN, 2001). 
Tais desafios e reformas do pensamento envolvem de forma direta a Educação em geral e a Educação Ambiental, em especial, aquela que se assume e se faz acontecer dentro das perspectivas crítica, emancipatória, libertária e transformadora. Ou seja, há que se reconhecer as diferentes concepções e respectivos paradigmas envolvidos nesses desafios educacionais e assumir posiçôes teóricas e epistemológicas, migrando da estrutura educacional fragmentária para um pensamento complexo e transdisciplinar (ZWIEREWICZ, 2019). A epistemologia da complexidade, o diálogo de saberes, a transdisciplinaridade são terrenos férteis para quem ousa cultivar outras aprendizagens e práticas educativas, ou ecoformativas, de acordo com Torre, Moraes e Pujol (2008), articulando esforços que possam propiciar uma (trans)formação dos sujeitos, dos coletivos e das estruturas sociais e instituições que os condicionam. Processos possíveis na medida em que se consegue integrar subjetividade e objetividade, ou seja, produção de intersubjetividade na construção de conhecimento sensível e inteligível superando a fragmentação do conhecimento e das relaçóes humanas com a natureza e a vida (MATAREZI; KOEHNTOPP, 2017). Evidencia-se o papel da Educação Ambiental para a criação e manutenção de espaços, tempos de formação e diálogos qualificados diante de conflitos, uma vez que estes estão na origem e essência da Questão Ambiental, que permitam a autocompreensão e o autoconhecimento.

Refletir sobre a complexidade ambiental abre um estimulante espaço para compreender a gestaçáo de novos atores sociais que se mobilizam para a apropriação da natureza, para um processo educativo articulado e compromissado com a sustentabilidade e a participação, apoiado numa lógica que privilegia o diálogo e a interdependência de diferentes áreas de saber. Mas também questiona valores e premissas que norteiam as práticas sociais prevalecentes, isto implicando numa mudança na forma de pensar, uma transformação no conhecimento e das práticas educativas. (JACOBI, 2004, p. 28).

A Educação Ambiental definida como um processo que busca “[...] desenvolver uma população que seja consciente e preocupada com o meio ambiente e com os problemas que lhes são associados" (Cap. 36 da Agenda 21, 1992), é uma alternativa necessária e urgente a ser implantada nos diversos setores da sociedade. Possibilitar atividades e projetos, também se faz 
importante e tem por objetivo sensibilizar e engajar a população nas questóes ambientais, no intuito de modificar pensamentos e possibilitar a promoção de transformações individuais e coletivas que contribuam com a transição para sociedades sustentáveis.

No campo da Educação, Paulo Freire considerava sua educação libertadora como um ato criativo por excelência. Para o autor, "quando o homem compreende sua realidade pode levantar hipóteses sobre o desafio dessa realidade e procurar soluçôes. Assim pode transformá-la e com seu trabalho, pode criar um mundo próprio, seu eu e suas circunstâncias." (FREIRE, 1979, p. 16). Uma vez que, "servindo à libertação, se funda na criatividade e estimula a reflexão e a ação verdadeira dos homens sobre a realidade, responde à sua vocação, como seres que não podem autenticar-se fora da busca e da transformação criadora." (FREIRE, 1988, p. 47).

Para despertar a consciência ecológica, é necessário, primeiramente, sensibilizar, no intuito de ressignificar atitudes e valores, pois as sensaçóes constroem valores, possibilitando a aproximação entre o ambiente, a mente e a alma. Neste sentido, trabalhar com o contexto, com as sensaçóes e com o lúdico é uma excelente forma de propiciar uma aprendizagem espontânea e natural no processo de construção do conhecimento ambiental.

A formação de processos de ensino e aprendizagem transdisciplinares deve ser baseada na construção de metodologias pedagógicas que permitam o engajamento, a autonomia, o protagonismo e o sentipensar (MORAES, 2019), para que, levando em conta os conhecimentos prévios dos estudantes, bem como, suas cosmovisóes e experiências, propiciem a prática, as vivências e as trocas, culminando na sensibilização ambiental durante um processo coletivo, investigativo, reflexivo e criativo.

Paulo Freire (1988) reconhecia a importância das várias linguagens para o processo da aprendizagem, inclusive das artes como inicializadora dos processos de descoberta na educação, sendo comum em seu trabalho a incorporação de imagens, a partir das quais os educandos metaforizavam e ressignificavam suas vidas e suas lutas (CASTELL, 2007).

Através desta ótica, surge a dinâmica da Árvore Semântica do Conhecimento (ASC), atividade pensada no conhecimento histórico e relacionadas ao sentipensar. A ASC que objetiva: mapear os conhecimentos dos estudantes acerca dos diversos problemas ambientais, avaliar as conexóes entre as "consequências" e as "soluçôes" de problemas ambientais verbalizadas 
pelos mesmos e propiciar um ambiente de troca de experiências, cosmovisóes e reflexôes. As razóes da utilização da árvore para compor esta dinâmica foram: a familiaridade dos estudantes com a planta e seu significado, as diversas ramificaçôes e possibilidades de configuraçôes da sua estrutura, a conectividade entre o invisível e o visível (raízes como invisível que dá vida a tudo que se vê, tronco, ramos, folhas e frutos), os seus ciclos sazonais e de vida duradouro e pela sua fisiologia.

$\mathrm{O}$ entendimento das relaçóes humanas com o meio, pode ser trabalhado em analogia ao funcionamento de uma árvore. As raízes são a base da árvore, provendo os nutrientes (sustento) e fortalecendo o restante da estrutura, elas seriam as "causas" da atividade. Já o tronco representaria as "palavras-chave", pois é o que conecta, sendo o caminho entre as raízes e folhas; e as folhas seriam as "consequências", o que nasce a partir das raízes (causas) e do tronco (palavras-chave).

Os problemas ambientais vivenciados (palavra-chave) e seus impactos (consequências) são perceptíveis, fáceis de visualizar, assim como, a estrutura do caule e folhas de uma árvore. Porém, as causas que nutrem estes problemas normalmente não são visíveis no primeiro momento, tão pouco as atitudes que os nutrem e fortificam. É necessário ampliar o olhar, refletir sobre o funcionamento das partes para o entendimento do todo e assim possibilitar a busca por soluçôes.

Esta dinâmica é uma das atividades que compóem o Projeto Oceanos, um projeto de Extensão Universitária que trabalha com estudantes em situação de vulnerabilidade social e acadêmicos da universidade, objetivando desvelar e refletir sobre os problemas ambientais que assolam o planeta por meio de atividades com metodologias criativas que despertem a reflexão sobre estas problemáticas e proporcionem a mudança de hábitos e valores, de acordo com padróes mais sustentáveis à realidade atual.

A ASC foi aplicada em 2018 e 2019, com a realizaçáo de algumas modificaçóes em 2019, visando à melhora metodológica. Neste artigo, traçase um paralelo entre as aplicaçóes da dinâmica, descrevendo os pontos modificados, relatando seus resultados e sugerindo novas melhorias para próximas aplicaçôes. 


\section{Metodologia}

O presente artigo relata e analisa a vivência de uma dinâmica elaborada no Projeto Oceanos. A pesquisa teve abordagem quali-quantitativa e contou com a análise de duas práticas teórico-metodológicos desenvolvidas por docentes e extensionistas que trabalham com educação ambiental de maneira interdisciplinar.

As práticas foram aplicadas para dois grupos distintos: um no ano de 2018, com 200 estudantes divididos em 4 turmas e outro, no ano de 2019, com 60 estudantes divididos em 2 turmas, todos no contraturno do seu período escolar, com idades entre 14 e 18 anos, em situaçáo de vulnerabilidade social. A atividade sofreu algumas modificaçóes de um ano para o outro, isso ocorreu como proposta de melhoria metodológica. Os resultados destas práticas possibilitaram a compreensão da percepção do discente sobre os seus conhecimentos a respeito do meio ambiente e sustentabilidade. Também despertaram a reflexão de novas possibilidades de aplicação da atividade. Assim sendo, o grupo, após a realização das atividades, os dados sistematizados e com base nas experiências anteriores, discutiu os pontos fortes da atividade e trouxe um novo formato para a mesma, os quais serão apresentados neste artigo.

Em 2018, a atividade dividiu-se em duas partes principais. Primeiramente, instruiu-se os estudantes se separarem em grupos de aproximadamente cinco integrantes, cada grupo sorteou um "problema”, três "folhas pardas" sem nenhuma inscrição e três "folhas verdes" também sem inscrição, disponibilizados em um balaio. Cada grupo discutiu isoladamente sobre o "problema ambiental" sorteado, analisando as suas "consequências" e "soluçôes", anotando-as, respectivamente nas folhas pardas e verdes. $\mathrm{Na}$ sequência, socializou-se com a classe, e os problemas foram discutidos pelos grupos. Para isso, projetou-se uma árvore seca na parede, para que cada grupo colasse na base de um galho da árvore o "problema"; neste mesmo galho, as consequências nas "folhas pardas" e as "soluçôes" descritas nas folhas verdes, coladas sobre as folhas pardas, em um processo alusivo à recuperação de uma árvore morta.

Da mesma maneira, no ano seguinte, em 2019, projetou-se uma árvore seca, sem folhas ou raízes no quadro; cada grupo formado por dois ou três estudantes, selecionou uma única palavra-chave gerada individualmente na 
atividade anterior resultante da reflexão realizada pelo espetáculo "Onda de Desperdício” do Projeto Água Viva, parceiro do Projeto Oceanos, que tem como objetivo promover a conscientização da água como um dos patrimônios mais preciosos da humanidade. A partir desta palavra-chave, discutiu-se em seus grupos e escreveu-se em retângulos, uma "causa" ao meio ambiente gerada por esta palavra-chave (atividade da semana anterior), representando as raízes daquela árvore. Depois, nas folhas das árvores, verdes ou pardas, escreveram-se as "consequências" geradas pela causa e pela palavra-chave, sendo que as folhas verdes representaram consequências positivas e as pardas consequências negativas. Feito isso, cada grupo colou as palavras chaves no tronco, as consequências nas folhas e as causas nas raízes e justificou estas escolhas em mini apresentaçóes. Para finalização, ocorreu um momento reflexivo coletivo, onde os estudantes pensaram nas suas árvores ideais e no que precisava ser feito para alcançar um ambiente favorável para o crescimento saudável daquelas árvores em comparação à nossa ASC, resultando em um diálogo profundo e com grande potência de ação.

Durante todo o percurso da pesquisa, extensionistas e professores realizaram anotaçóes dos resultados das atividades no Diário de Bordo. Estas informaçóes foram sistematizadas, discutidas, categorizadas e analisadas, objetivando refletir sobre os pontos fortes dessa metodologia, com vistas a discuti-las para a concretização deste estudo e para servir de modelo para futuras aplicaçóes.

\section{Resultados e Discussóes}

Os dados para a análise e discussão deste trabalho foram extraídos dos Diários de Bordo elaborados durante e após cada atividade concluída. Também analisaram-se fichas preenchidas pelos estudantes. Iniciou-se esta avaliação a partir das "consequências" apresentadas pelos estudantes, as quais foram construídas coletivamente mediante as palavras-chaves que cada equipe possuía. As palavras e/ou expressóes semelhantes foram agrupadas, categorizadas e intituladas posteriormente, seguindo o procedimento do "acervo", respeitando a exclusão mútua, homogeneidade, pertinência, objetividade/fidelidade e produtividade, segundo recomendaçóes de Bardin (2016). Posteriormente, analisou-se estes dados categorizados por meio de Análise de Correspondência Múltipla (ACM). 
Em 2018, as palavras-chaves, ou seja, os problemas ambientais foram delineados pelos monitores do Projeto de Extensão Oceanos, e estes, "sorteados" pelos estudantes para discutirem as suas consequências. Neste momento, percebeu-se que alguns problemas, como "desaparecimento de corais" e "microplástico" eram, não apenas os seus primeiros contatos com estes temas, mas estavam ainda muito distantes da sua realidade cotidiana, outros problemas causaram estranheza devido ao desconhecimento da definição da palavra, foi o caso para "potabilidade" e "agrotóxico". Apesar deste segundo grupo de situação ter sido mais fácil de ser contornado, ainda assim, percebeu-se que, mesmo acompanhados pelos monitores, a elaboração e discussão dos seus impactos no ambiente, ou seja, as "consequências" apresentaram dificuldades. Por outro lado, o problema "enchente" trouxe discussóes com riqueza e pertinência na argumentação, onde aspectos tão complexos e profundos, como "depressão" e "conscientização" da população, foram apontados, respectivamente, como consequência e solução para este problema, e assim, se diferenciando de qualquer outra discussão, quando aspectos afetivos se manifestaram pela primeira vez, mas ainda de forma isolada. A "diminuição de peixes" nos rios, foi outro problema que gerou momentos de rica discussáo entre os estudantes, permeando termos como "período de defeso", "pesca excessiva" ou "criação em cativeiro" com uma coerência tão bem fundamentada semelhante a uma discussão entre especialistas. Mas o que há de comum entre estes problemas?

No primeiro caso, ao se depararem pela primeira vez com o problema que lhes foi apresentado, mesmo tendo o acompanhamento dos monitores, este apoio apenas os orientou para a busca de suas consequências ou soluçóes, não sendo suficiente para uma compreensão do assunto. E, no segundo caso, a maioria dos estudantes já havia vivenciado e experienciado o problema na prática. A regiáo de Itajaí é marcada por um histórico de recorrência de enchentes, e a experiência desses desastres, muitas vezes traumatizantes, marca a comunidade com sofrimento ao relembrar das perdas causadas por estes eventos, cuja dimensão social não pode ser esquecida (SANTOS; TORNQUIST; MARIMON, 2014). Além do município estar localizado em uma região litorânea fortemente dependente da economia pesqueira, sendo muitos moradores ligados diretamente à sua cadeia produtiva, sendo filhos ou parentes de pescadores. Desta forma, tanto "enchente" como "diminuição de peixes", provavelmente, são assuntos do seu cotidiano, fomentando a 
importância do conhecimento prévio na aprendizagem significativa (PIAGET, 2013; AUSUBEL, 2003).

Dois aspectos parecem ter sido necessários e essenciais para a efetivação da ASC: 1 - a sensibilização para a contextualização aos problemas ambientais e 2 - conhecimento prévio sobre os diferentes saberes dos estudantes. Freire (1996) destaca a importância do aprender tendo como referência o dia a dia no processo de aprendizagem, buscando o que é significativo e criando possibilidades para a construção do conhecimento a partir do próprio sujeito.

Desta forma, realizaram-se pequenas adaptaçóes, para a sua reaplicação no ano seguinte. A sensibilização dos estudantes para o tema trabalhado, a problemática ambiental, ocorreu, no primeiro ano, por meio da apreciação de um vídeo curto relacionado ao tema, seguido de uma discussão em uma roda de conversa, antes da realização da ASC. Pelos resultados obtidos, parece não ter surtido o efeito desejado o qual seja, a sensibilização dos estudantes para a problemática ambiental. Assim, no ano seguinte, substituiu-se este vídeo por uma apresentação do Espetáculo Onda de Desperdício, do Projeto de Extensão Água Viva da UNIVALI, cujo foco é o Lixo Plástico nos Oceanos (MARIN; KUROSHIMA, 2020). Uma semana antes da realização da ASC, deslocaram-se os estudantes para um teatro a fim de assistirem ao espetáculo. Envolvendo ciência e arte, este espetáculo procura através de uma combinação harmoniosa entre dança, música e imagens, aflorar e expandir os diferentes sentidos de cada espectador, permitindo assim, trabalhar conjuntamente os pensamentos e os sentimentos; a razão e a emoção, impactando o modo de percepção do seu entorno e o (re)conhecimento desta realidade, de forma ampliada e complexa (RIBEIRO; MORAES, 2014). Por apresentar este potencial, já reconhecido devido a outras apresentaçóes, selecionou-se este espetáculo para a sensibilização e contextualização ao tema dos problemas ambientais.

Logo após a apresentação deste espetáculo, houve uma roda de conversa, com uma forte discussão sobre as suas principais mensagens transmitidas e todos finalizaram sintetizando a sua representação, uma única palavra utilizada para iniciar a atividade da ASC, no próximo encontro da semana seguinte. A partir destas palavras, construíram-se coletivamente, as "causas" e as "consequências" definidas por elas. As causas seriam os "problemas ambientais", e esta foi a segunda "adaptação" para a reaplicação da ASC. Diferentemente do ano anterior, quando sortearam-se pelos 
estudantes os "problemas ambientais" já elaborados e estes os recebiam passivamente, desta vez, alterou-se a proposta, permitindo que os "problemas ambientais", ou seja, as "causas às palavras-chaves" fossem construídas coletivamente, favorecendo a interação entre diversos atores, valorizando seus diferentes saberes e cenários de aprendizagem, incitando e permitindo a aprendizagem significativa (MOREIRA; RIBEIRO, 2016), na tentativa de fazer o estudante interagir com o assunto em questão, e o problema ambiental emergisse a partir de seus conhecimentos prévios (PELIZZARI et al., 2002).

As mudanças repercutiram significativamente e foram observadas de imediato, ao longo de todo o processo e realização da ASC. Iniciando pela elaboração, individualmente, das palavras-chaves, logo após a discussão em roda de conversa sobre as percepçôes, significações e representatividades do espetáculo. O espetáculo mostrou como tema central a poluição de microplásticos nos oceanos. No entanto, nas palavras verbalizadas e registradas pelos estudantes sobre as representatividades deste espetáculo, surpreendentemente, não surgiu nenhuma que se assemelhasse à poluição ou microplástico ou oceano. Porém, surgiram palavras manifestando emoção e sentimento como dor, empatia e tristeza. Apesar de o espetáculo abordar como tema central a poluição marinha, a arte pode ter impulsionado os sentimentos permitindo que aflorassem as emoçóes dos estudantes. Impressionantes foram, ainda, as "consequências" relacionadas pelos estudantes a partir destas palavras-chaves focadas nas emoçóes. Palavras relacionadas diretamente ao espetáculo, como "oceano", foram pouco lembradas pelos estudantes ao relatarem as consequências ao problema ambiental. No entanto, surgiram as palavras "meio ambiente" e "desequilíbrio ambiental" que abordam o problema ambiental de forma mais ampla, incluindo não apenas os problemas envolvidos com os ecossistemas aquáticos, como os oceanos, apresentados pelo espetáculo. Poder-se-ia, assim, "interpretar" a escolha destas palavras como uma ampliação do processo de aprendizagem impulsionado pelas questôes afetivas, indo além do simples problema apresentado, mas com uma visão mais globalizada?

Quando a construção do conhecimento ocorre conjuntamente entre “[...] sentimento/emoção e pensamento/razão [...], impactando os modos de perceber e de interpretar a realidade e suas implicaçóes no âmbito cognitivo e emocional/afetivo[...]" (RIBEIRO; MORAES, 2014, p. 44), pode-se denominar de sentipensar, e, muitas vezes, ampliando e impulsionando o 
processo de aprendizagem. Assim, neste caso, o espetáculo certamente atuou como um novo modo de "conhecer e produzir conhecimento" a partir de uma "[...] pulsão religadora de conhecimentos, saberes e culturas, em uma visão transdisciplinar, inspirada no pensamento complexo [...]" (SANTOS; NASCIMENTO; SUANNO, 2016, p. 460).

Para uma avaliação mais detalhada e comparativa entre estes dois momentos, categorizaram-se todas as palavras geradas nas discussóes sobre as consequências aos problemas ambientais, seja a partir das palavras-chaves sorteadas (2018) ou elaboradas pelos estudantes (2019, unindo-as quando similares conceitualmente, as quais foram plotadas e analisadas estatisticamente.

Em 2018, as palavras mais presentes como "consequências" aos problemas ambientais foram "poluição" (10,1\%) e "doença" (9,4\%); e, na outra extremidade, as palavras "lixo", "potável", "consumo", "planta” e "afetividade", cada uma com $0,7 \%$ de presença, foram as menos presentes (Fig. 1). Este conjunto de palavras, quando categorizadas, apontaram as mais frequentes como "água" e "poluição", totalizando $43 \%$ de frequência, e a "afetividade", a categoria menos frequente $(0,7 \%)$. Esta frequência foi bem diferente das palavras e categorias apresentadas em 2019, onde, contrariamente, "afeto" (19\%), "animal" (17\%) e "homem" (10\%) foram as mais frequentes, e portanto, as categorias "organismo" (20\%) e "afeto" (19\%) ficaram da mesma forma, sendo as mais evidentes.
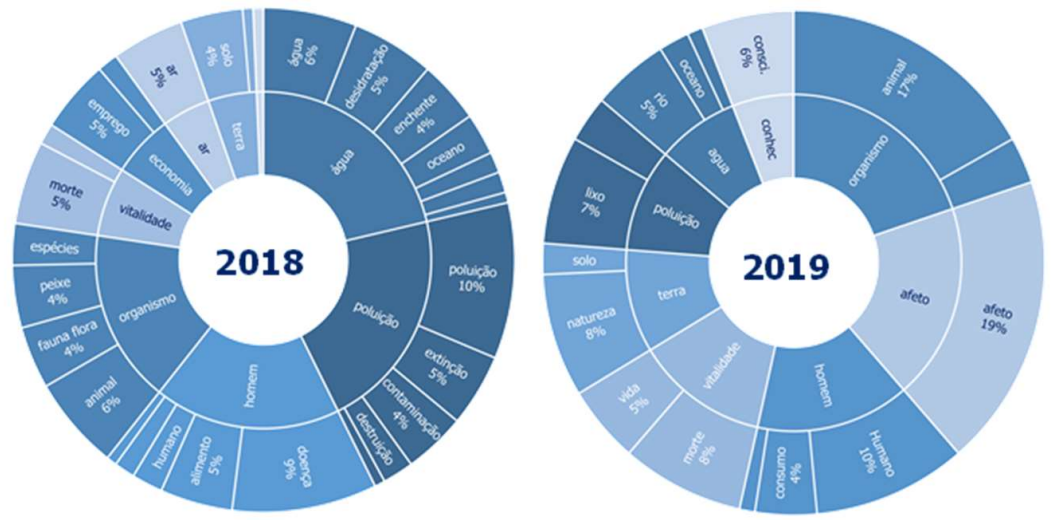

Figura 1: Distribuição da frequência percentual das principais palavras durante as atividades da "Árvore Semântica” realizadas em 2018 e 2019 e suas respectivas categorias. 
Estes resultados corroboram com a discussão prévia, e a distribuição multivariada das palavras na análise de componentes principais definiu dois grupos distintos entre 2018 e 2019 (Fig. 2). A abordagem metodológica foi fundamental na diferença dos resultados entre os anos, enquanto em 2018, apresentou-se o processo pedagógico aos estudantes sem a sua participação ativa, evidenciando a falta de conhecimentos prévios sobre a maioria das problemáticas ambientais apresentadas e resultando na superficialidade das conexôes nas relações entre causas/consequências na atividade, observadas não apenas durante a execução das ASC, mas nas reflexóes e discussóes que aconteciam após as suas realizaçôes; em 2019, o processo pedagógico foi participativo, de caráter autônomo e protagonista, onde os estudantes definiram suas palavras-chave a partir de uma epítome, apresentando-as carregadas de afetos (Fig. 2), sendo a principal causa na distinção entre os grupos nos diferentes anos, levando a conexões mais complexas nas relações de causa/efeito, visão mais ampla acerca das problemáticas ambientais e, consequentemente, mais engajamento e diálogo, devido ao sentimento de pertencimento pela presença em todas as etapas do processo de ensinoaprendizagem da ação proposta. "Transcendendo as fronteiras do conhecimento disciplinar para ampliar a compreensão sobre o ser humano e sobre o mundo presente, assumindo, para tanto, o desafio de pensar complexo.” (SILVA; SUANNO, 2017, p. 328). 


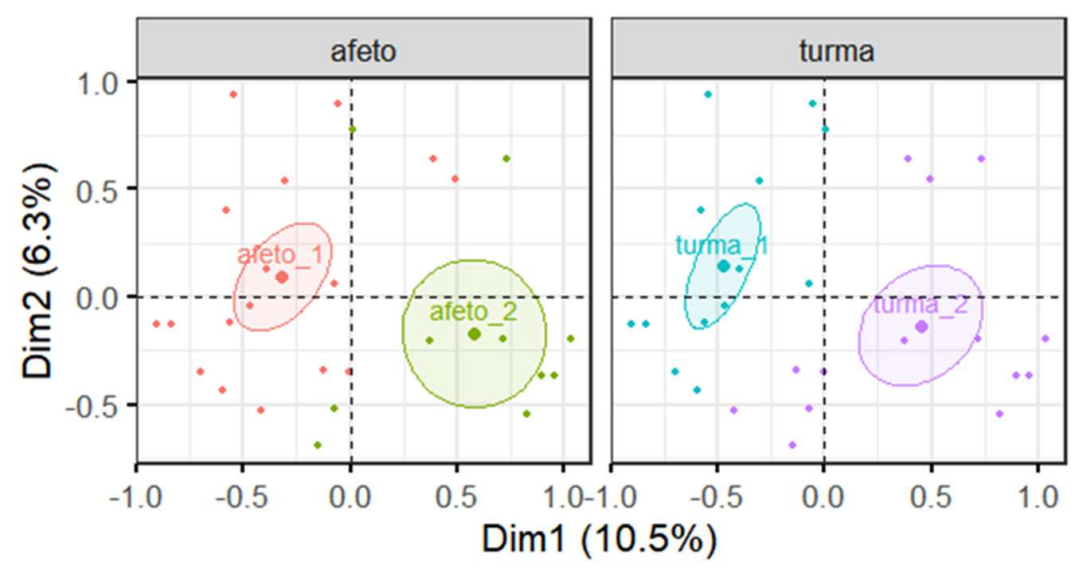

Figura 2: Dispersão das palavras por grupos de alunos no primeiro plano fatorial, destacando a influência da categoria "afeto" na identificação dos diferentes grupos. "Turma 1"- 2018, “Turma 2" - 2019, "afeto 1"- ausência e "afeto 2" - presença de palavras relacionadas à afetividade.

\section{Consideraçóes finais}

Nessa perspectiva, a avaliação comparativa destas aplicaçóes da ASC nestes dois momentos e com o auxílio das experiências anteriores da equipe com atividades criativas, interdisciplinares e transdisciplinares, afirma-se que a ASC pode ser ainda uma inovação didática no processo de ensino e aprendizagem contemplando alguns objetivos listados por Silva e Suanno (2017), Morin (2001) e Behrens (2003): permite o pensamento complexo; possibilita a transdisciplinaridade entre saberes científicos, filosóficos, poéticos, artísticos, etc. Possibilita compreender o mundo presente, promovendo articulação entre o saber científico e o popular; ampliando a consciência humana, e buscando nesta formação a religação entre a razão e a emoçáo, o reencontro com o outro e com a natureza, em uma constante transformação, evidenciando a sua complexidade e completude.

Novas adaptaçóes podem ser contempladas no método pedagógico tendo em vista o público atendido e o objetivo previsto, não apenas para questôes relacionadas à educação ambiental, mas também outras temáticas em que se considerem os conhecimentos prévios, a complexidade das conexóes 
entre conceitos, a construção coletiva, o aprendizado significativo e participativo, a sensibilizaçáo, a partir da epítome e o trabalhar do sensível e da razão. Apresenta-se na Fig. 3 um esquema da proposta da ASC para novas aplicações que observa a evoluçáo da dinâmica, trazendo a importância da sensibilização significativa por meio do epítome, da participação do sujeito na construção da ação e da valorização do pensamento individual no coletivo.

Portanto, coloca-se como uma proposta para essa atividade os seguintes itens:

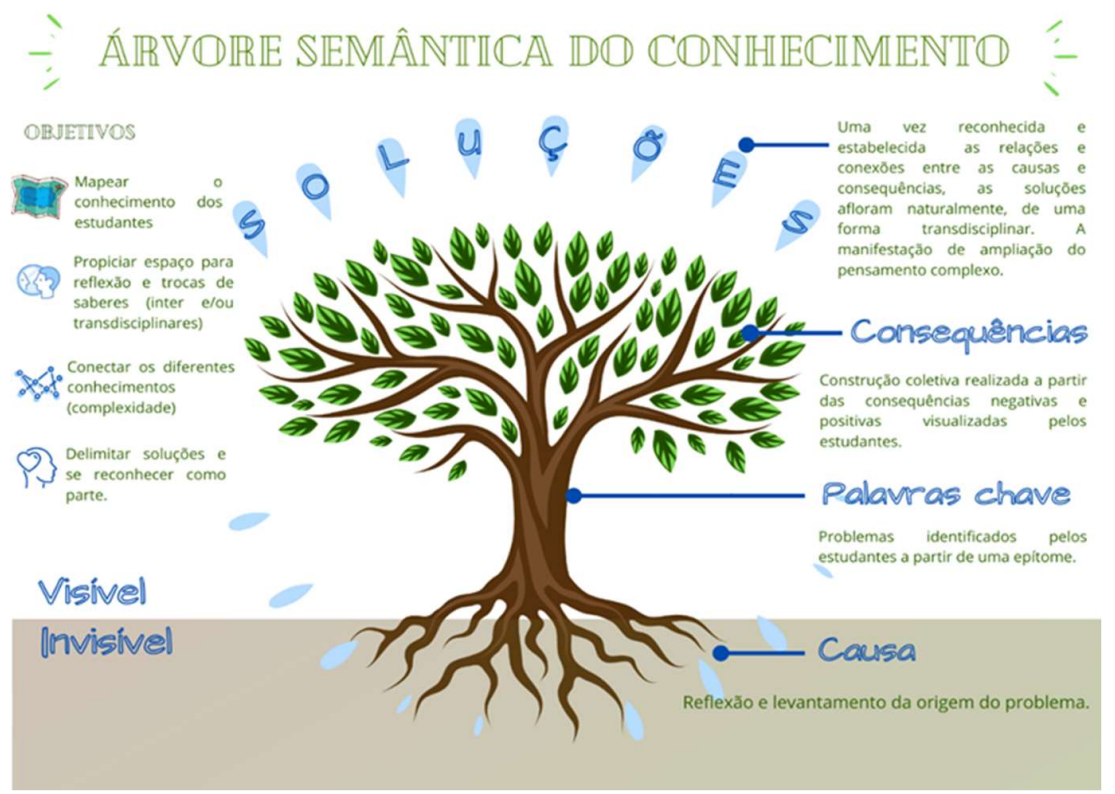

Figura 3: Esquema da Proposta metodológica da Árvore Semântica do Conhecimento - ASC, com as suas principais características.

1- PALAVRAS-CHAVE: sugerir aos estudantes a discussão a respeito, entre pares, a partir de uma epítome. Mesmo que a escolha tenha sido individualizada, que permita uma socialização para momentos de reflexão.

2 - CAUSA: inicialmente, promover reflexão sobre as problemáticas atuais. Esta atividade deve ser cuidadosamente organizada, de forma a encontrar estratégias onde o estudante tenha possibilidades (e se sinta 
motivado) para buscar novas informaçóes, refletir sobre o assunto, discutir com o outro, enfim, possa efetivar ligaçóes do problema com seu cotidiano.

3 - CONSEQUÊNCIA: o ambiente deve propiciar um espaço para a construção coletiva, participativa, dialógica, que permita uma troca de saberes entre os sujeitos participantes.

4 - SOLUÇÓES: no momento em que as relaçóes e conexôes entre causa e consequências tiverem sido compreendidas pelos estudantes, as soluções emanarão naturalmente, e a atividade deve propiciar momentos e espaços para que isso aconteça.

\section{Agradecimentos}

À Vice-Reitoria de Extensão e Assuntos Comunitários da UNIVALI e à EMCT pelo apoio financeiro e logístico para a execuçáo dos Projetos de Extensão Oceanos. Ao Instituto Crescer - Movimento Cidadania e Juventude do município de Itajaí, parceiro do Projeto de Extensão Oceanos. Ao Instituto Federal de Educação, Ciência e Tecnologia do Paraná. A todos os bolsistas e voluntários dos Projetos de Extensão, professores e funcionários da UNIVALI que participaram efetivamente do planejamento e execução das atividades descritas neste trabalho. À CAPES, pelo apoio financeiro.

\section{Referências}

AUSUBEL, D. P. Aquisição e retenção de conhecimentos: uma perspectiva cognitiva. Lisboa: Plátano Ediçôes Técnicas, 2003.

BARDIN, L. Análise de conteúdo. São Paulo: Ediçôes 70, 2016.

BEHRENS, M. A. O paradigma emergente e a prática pedagógica. 3. ed. Curitiba: Champagnat, 2003.

CAPRA. F. A teia da vida: uma nova compreensão científica dos sistemas vivos. São Paulo: Cultrix, 1996.

CASTELL, C. H. G. P. Metaforizando a vida na terra: um recorte sobre o caráter pedagógico do Teatro - Fórum e sua mediação nos processos de transição agroecológica e cooperação em Rio Grande - RS. 2007. Tese 
(Doutorado em Educação) - Faculdade de Educação, Universidade Federal do Rio Grande do Sul, Porto Alegre, 2007.

Conferência das Naçôes Unidas Sobre Meio Ambiente e Desenvolvimento Agenda 21. Rio De Janeiro, 1992.

FIGUEIREDO, O. A controvérsia na educação para a Sustentabilidade: uma reflexão sobre a escola do Século XXI. Interaç̧óes, v.2, n.4, p. 3-33, 2006.

FREIRE, P. A pedagogia do oprimido. Rio de Janeiro: Paz e Terra, 1988.

FREIRE, P. Educação e mudança. São Paulo: Paz e Terra, 1979.

FREIRE, P. Pedagogia da autonomia: saberes necessários à prática educativa. Rio de Janeiro: Paz e Terra, 1996.

GADOTTI, M. Educação Integral no Brasil. Inovações em Processo. São Paulo: Instituto Paulo Freire, 2009.

JACOBI, P. Educação e meio ambiente: transformando as práticas. Revista Brasileira de Educação Ambiental. Brasília, v. no 2004, p. 28-35, nov. 2004.

MARIN, C. B.; KUROSHIMA, K. N. Da ciência à arte: Onda de Desperdício - Os perigos visíveis e invisíveis do lixo no mar. In: SILVA, M. E. D. (Org.) O meio ambiente e a interface dos sistemas social e natural 2. Ponta Grossa, PR: Atena, 2020. p. 288-298.

MATAREZI, J.; KOEHNTOPP, P. I. Conhecimento sensível e inteligível na abordagem metodológica Trilha da Vida. Revista Confluências Culturais, v. 6, n. 1, p. 69-81, 2017.

MORAES, M. C. Ecopedagogia, ecoformação e consciência planetária. In: VELASCO, J. M. G. (Org.) Experiencias Educativas - saberes, ecoformación, complejidad y transdisciplinariedad. La Paz, Bolívia: Prisa. 2019a. p.67-95.

MORAES, M. C. Saberes para uma cidadania planetária - Homenagem a Edgar Morin. Rio de Janeiro: Wake, 2019.

MOREIRA, J. R.; RIBEIRO, J. B. P. Prática pedagógica baseada em metodologia ativa: aprendizagem sob a perspectiva do letramento informacional para o ensino na educação profissional. Periódico Científico Outras Palavras, v. 12, n. 2, p. 93, 2016. 
MORIN, E. Os desafios da complexidade. In: Morin E. (Org.). A religação dos saberes. O desafio do século XXI. Rio de Janeiro: Editora Bertrand Brasil, 2001. p. 559-567.

PELIZZARI, A. et al. Teoria da aprendizagem significativa segundo Ausubel. Rev. PEC, Curitiba, v.2, n.1, p.37-42, jul. 2001-jul. 2002.

PIAGET, J. A Psicologia da Inteligência. Petrópolis: Vozes, 2013.

RIBEIRO, O. C.; MORAES, M. C. Criatividade em uma perspectiva transdisciplinar: rompendo crenças, mitos e concepçóes. Brasília: Liber Livro, 2014.

SANTOS, C. F.; TORNQUIST, C. S.; MARIMON, M. P. C. Indústria das enchentes: impasses e desafios dos desastres socioambientais no Vale do Itajaí. Geosul, v. 29, n. 57, p. 197-216, 2014.

SANTOS, L. P.; NASCIMENTO, C. de; SUANNO, M. V. R. Estágio transdisciplinar: outra formação, outra educação, outro ensino, outra aprendizagem. Polyphonia, v. 27, n.1, p. 455-474, 2016.

SILVA, C.C.; SUANNO, M. V. R. Perspectivas emergentes no estágio curricular obrigatório do curso de pedagogia. Educativa. Goiânia, v. 20, n 2, p.315-338, maio./ago. 2017.

TORRE, S.; MORAES, M. C.; PUJOL, M. A. Transdisciplinaridade $e$ ecoformação: um novo olhar sobre a educação. Vidigal S (trad.). São Paulo: Triom, 2008.

ZALASIEWICZ, J. et al. The Anthropocene: a new epoch of geological time? Philosophical Transactions of The Royal Society A, v. 369, n. 1938, p. 835-841, 2011.

ZWIEREWICZ, M. Complexidade, transdisciplinaridade e ecoformação em pesquisas com intervenção: experiências do mestrado profissional da UNIARP. In: VELASCO, J.M.G. (Org.) Experiencias Educativas - saberes, ecoformación, complejidad y transdisciplinariedad. La Paz, Bolívia: Prisa. 2019. p.45-55.

Recebido em: 15 ago. 2020

Aceito em: 12 set. 2020 